\title{
ON CERTAIN FORMS OF COMMON AMERICAN BUTTERFLIES.
}

\author{
By Austin H. Clark \\ Smithsonian Institution, Washington, D. C.
}

In any large series of butterflies of any single species the individuals are seen to be divisible into various forms. These forms are of two types, those due to a response to environmental conditions, that is, to a response to the chemistry and physics of their environment, and those due to physiological indiosyncracies on the part of certain individuals, that is, to their internal chemical and physical condition.

Examples of the first are cold and hot and wet and dry forms and local varieties. Examples of the second are alternative forms in either sex or in both sexes, and most of the variants usually classed as "aberrations."

There is no sharp distinction between these two classes, for a species may have, for instance, a long range of alternative forms in one region and none in another, or variants of one or several types may be frequent in one area and rare or unknown elsewhere, or may occur only in certain years, which clearly has to do with environment.

In the following pages attention is called to a few forms from among our common native butterflies which, by analogy with corresponding forms elsewhere, seem susceptible of interpretation as wet and dry forms.

It is presumable that a wet form of a butterfly is a form adapted to developing in the presence of an amount of moisture equalling or in excess of the maximum requirements. This moisture may be furnished either in the form of abundant water in the food, or abundant water available for ingestion with the food. A dry form would be a form living in the younger stages on food with an amount of water at or near the minimum requirements. This might be due (1) to seasonal variation in the precipitation, (2) to differences in soil conditions, as between bogs and well drained dry uplands, or to seasonal variation in the condition of the food 
plant, as for instance the moist condition up to the time of flowering and the dry condition after flowering or toward the end of the growing season.

Wet and dry forms are more or less independent of temperature. For instance, all the forms of Eurymus eurytheme about Washington in the summer are clear yellow on the under surface of the wings and in the autumn are heavily infuscated. But wet forms seem to be very sensitive to dessication in the extreme cold of winter if they hibernate as adults or as pupæ.

Here as elsewhere there is to be remarked a considerable difference in habits between wet and dry forms, the latter being always the more active.

Junonia cœna.-The common buckeye occurs in the District of Columbia in two quite different forms.

In the usual form the fore wings measure about $27 \mathrm{~mm}$. in length in the females and about $24 \mathrm{~mm}$. in the males. The ground color above is a medium brown. Beneath the ground color of the hind wings and of the apex of the fore wings is light gray, usually slightly tinged with buff, and there are two conspicuous oval black spots about as broad as, or narrower than, an interspace which are narrowly ringed with buff not far from the outer margin of the hind wings.

The wings are dry and brittle, and nearly all the individuals caught are nicked or more extensively damaged.

This form is exceedingly alert and active and a very strong flier. If alarmed it flies rapidly away, often not pausing before it is out of sight. It is fond of flowers, especially white flowers rising well above the grass, and for resting it always chooses the summit of a tall weed or of a tall dead stem or the bare ground from which it can easily dart away in any direction.

It is found throughout the District, most abundantly in dry open country, and is not infrequently noticed in the parks and about the streets of Washington.

In the other form the fore wings are about $30 \mathrm{~mm}$. long in the females and about $28 \mathrm{~mm}$. long in the males. On the upper surface the ground color is dark and the brown of the fore wings and of the outer half of the hind wings sometimes shows dark green metallic reflections. On the under 
side the whole of the hind wings and the apical portion of the fore wings is dull pinkish red, often quite uniform, but usually darkest in a long irregular narrow triangle bordered by irregularly crenulate lines running from a base near the outer angle to an apex near the anal angle. This triangle often includes two small oval blue spots narrowly ringed with lighter, or some traces of such spots. The wings are somewhat fuller and less angulated than the wings of the preceding form.

The wings are curiously soft, and are rarely broken or torn, though they may be rubbed. The insect always feels as if it had recently emerged from the chrysalis.

It is sluggish and rarely flies for more than fifty feet or so, alighting usually on the ground in thin grass or weeds. It is not shy and is easily captured. I have never seen it on a flower.

It is exceedingly local and is confined to boggy lowlands with an abundant growth of Agalinis purpurea on which the larvæ feed. It is very numerous in the restricted areas where it occurs, appearing in late summer.

Not infrequently in late summer individuals of the small light form are taken in moist areas which show an approach to the large dark form in a greater or lesser development of pink markings on the under side of the hind wings. But as a rule the two forms are quite distinct, at least in this region.

As the large dark indolent form is strictly confined to wet meadows while the small light form is the only one occurring in dry situations, it is logical to consider the former as a "wet" and the latter as a "dry" form. Moreover, the differences between these two forms are essentially the same as those between the wet season and the dry season forms of the Asiatic Junonia orithya, J. almana and J. iphita.

In Asia the wet and dry forms of Junonia alternate. With us the wet form develops from eggs laid by the dry form, as in India. But it only develops in water-logged localities, the young of the dry form elsewhere being a new dry generation.

So far as known the wet form in the District of Columbia dies out completely during the winter. 
The wet form of our Junonia cœna in this region, therefore, is represented by local colonies leaving no descendents which originate from dry parents.

Cynthia atalanta.-Like the buckeye, the red admiral occurs in the District in two quite different forms. In boggy areas with an abundant growth of the false nettle (Bohmeria cylindrica) there appear in late summer large individuals which above are blackish instead of brown with the border of the hind wings redder than in the usual form and the band on the fore wings redder and narrower and crossed by black veins, and below are much darker, especially on the hind wings.

This form differs from the usual type just as the "wet" form of Junonia cœna differs from the "dry" form, occurs in the same localities, and appears in the same way in late summer.

It seems not to survive the winter, as all the numerous spring individuals caught in the places where the dark form is later to be found are of the small brownish form. It is to be interpreted as a "wet" form descended from "dry" parents and leaving no progeny.

Cynthia cardui.-Within the District, and throughout the whole of New England except for the southern coast, the painted lady when it occurs is represented by a large form with the fore wings slightly shorter than usual and sometimes very short, and the hind wings slightly broader and more rounded. The color is dark and brilliant, and the upper surface and the inner portion of the lower surface of the fore wings is strongly tinged with pink. The submarginal spots on the hind wings are usually large, and not infrequently on the upper surface show conspicuous blue centers.

This form, which is the only one found in the District and in most parts of New England in the summer and autumn, seems to be the "wet" form of this species which, like the corresponding forms of Junonia cana and of Cynthia atalanta, cannot survive the winter.

So far as I have been able to learn, wherever this form occurs exclusively this butterfly is of uncertain and more or less irregular appearance. It survives the winter only where the smaller, duller, longer winged form is to be found in the late summer.

The more or less irregular occurrence of this insect in 
great numbers over wide areas not permanently inhabited by it and its complete disappearance during the succeeding winter are readily explained if we recognize the existence of a "wet" form comparable to that of Junonia cana and Cynthia atalanta.

The "dry" females in the spring are very active and wander in every direction, scattering their eggs over a wide extent of territory. If they are numerous and if conditions are favorable they will become dispersed over regions far beyond the area where they passed the winter.

This species differs from the two just considered in being normally an inhabitant of semi-arid regions. Under the conditions found in the District and in the greater part of New England the young from over-wintered females develop into the large and brilliant "wet" form, which appears in July. The young of these summer butterflies, appearing on the wing in late August and September, are of the same form as their parents. But in the District spring individuals, which are not at all common and are only to be seen in the low ground near the river, are always of the "dry" form.

So apparently the reason for the irregular appearance of this butterfly is that in most of the area from which it is known its caterpillars develop into a form unable to survive the winter and its occurrence therefore is dependent on regular, more or less irregular, or occasional incursions of overwintered females from elsewhere.

Polygonia interrogationis and $P$. comma.-The foregoing interpretation of the forms of Junonia cona, Cynthia atalanta and C. cardui, and analogy with Polygonia c-album cognata and $P$. c-a. agnicula of the Himalayan region and P. c-a. hamigera of Japan, Corea and northern China, suggest a corresponding interpretation of the seasonal forms of Polygonia interrogationis and $P$. comma.

In the District of Columbia the light form of $P$. interrogationis is variable in color, some of the individuals being much darker than others, especially in the female. In $P$. comma the light form seems usually to be darker than in New England with more extensive infuscation of the hind wings, some individuals, indeed, being almost as dark as the dark form. In both species the shape of the wings is constantly different in the two forms, so that such indications of intergradation as occur are wholly in the color. 
The autumn brood of these butterflies is invariably of the light form. The summer brood is of the dark form, with which there are usually to be found a few individuals of the light form.

These forms probably reflect wet spring and dry summer conditions acting on the food plants.

In both species there is a wide difference in the habits of the two forms, the dark form tending to remain within a restricted area in or near woods and the light form scattering widely over open country. This recalls the difference in habits of the two forms of Junonia coena.

Eurymus eurytheme.-From the description of the succession of forms of the orange clover butterfly in Texas and elsewhere in the southwest it would seem that ariadne is a dry form of this species, keewaydin an intermediate form, and the deep orange eurytheme with a more or less brilliant violet iridescence in the males the extreme wet form.

In the District the earliest individuals to appear are of the extreme wet form, eurytheme. In July the keewaydin form appears, flying with the other until the end of the season and intergrading with it. Early in August the ariadne form appears, but it is scarce until after the middle of September when it becomes frequent, though not very common. It flies with the other two until the end of the season in October or November.

About Washington there is noticeable a difference in the distribution of these three forms. The deeply colored eurytheme is most numerous in the lower areas, especially along the river. The most intensely colored and the largest individuals are to be found in the wet meadows beyond Cabin John. In the higher country the individuals appear never to reach such a large size as they do here, while the relative proportion of the forms keewaydin and ariadne appears to be greater.

The forms ariadne, keewaydin and eurytheme, which appear in seasonal sequence in the southwest, about Washington seem to appear in response to very local conditions, permanent wetness in the boggy pastures and progressive drying in the higher areas, which accompany the general trend from wet spring to dry autumn. 

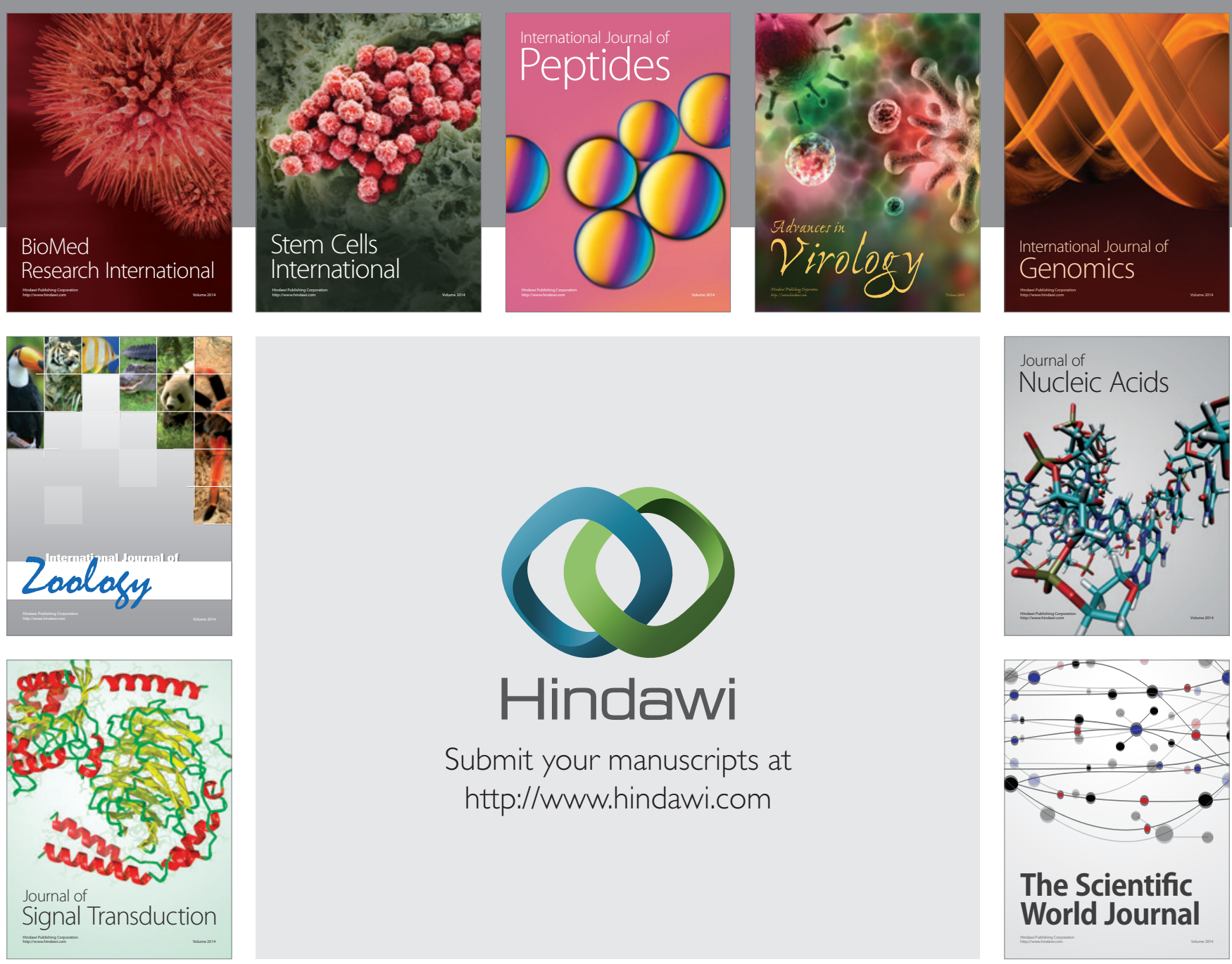

Submit your manuscripts at

http://www.hindawi.com
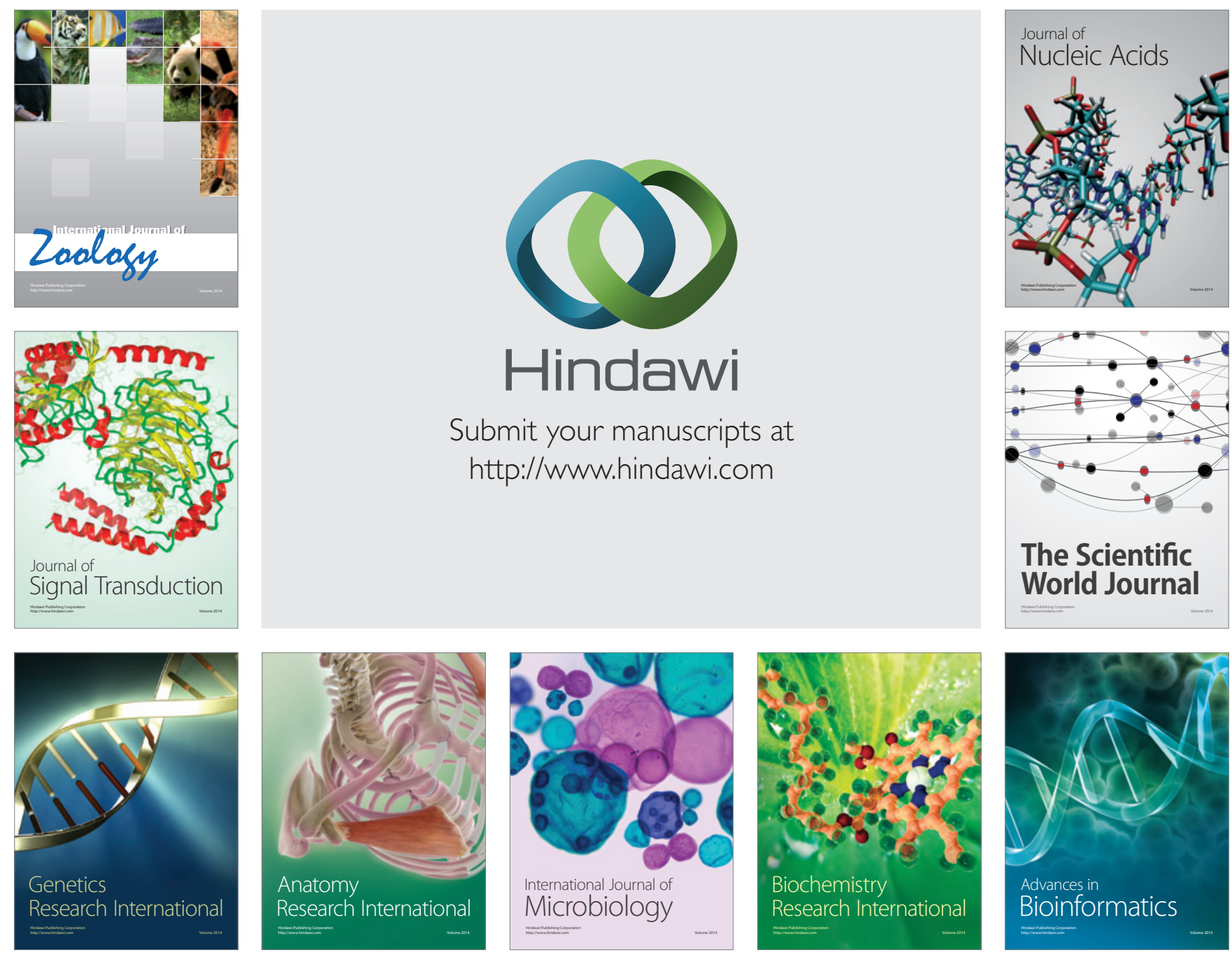

The Scientific World Journal
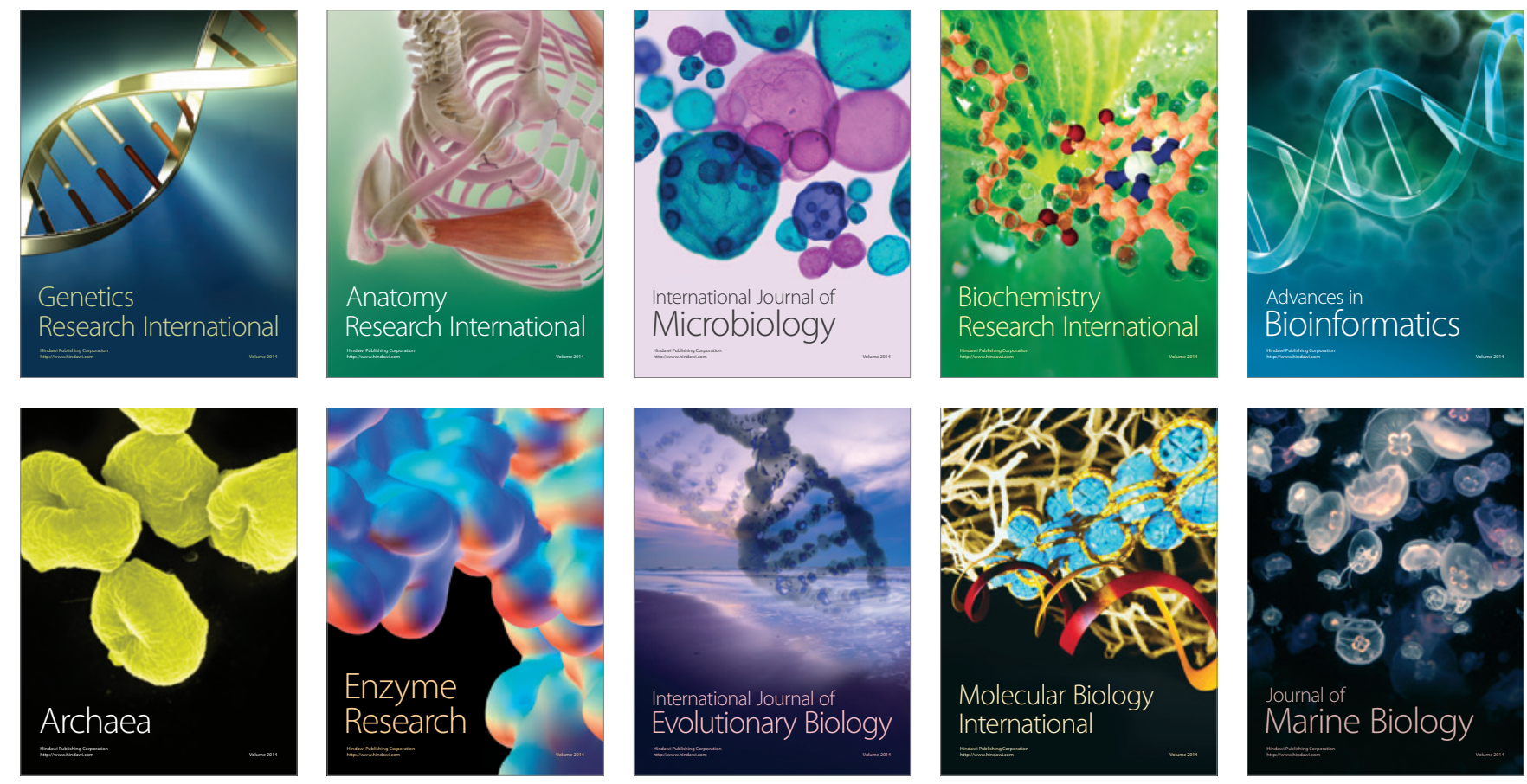